\title{
Amplitude of Sound Evoked Triceps Myogenic Potential Scales with Force
}

Marcello Cherchi ${ }^{1^{*}}$, Wafa El-Kholy ${ }^{2}$, Debra Shirley ${ }^{3}$ and Timothy C Hain ${ }^{1}$

${ }^{1}$ Department of Neurology, Northwestern University Feinberg School of Medicine, USA

${ }^{2}$ Department of Otolaryngology, Ain Shams University, Cairo, Egypt

${ }^{3}$ Discipline of Physiotherapy, University of Sydney, Sydney, Australia

*Corresponding author: Marcello Cherchi, Assistant professor, Northwestern University, Abbott Hall, 11th Floor Chicago, IL 60611-3078, USA; E-mail: mcherchi2@md.northwestern.edu

Received date: February 10, 2015; Accepted date: April 23, 2015; Published date: April 27, 2015

Copyright: $@ 2015$ Cherchi $\mathrm{M}$ et al. This is an open-access article distributed under the terms of the Creative Commons Attribution License, which permits unrestricted use, distribution, and reproduction in any medium, provided the original author and source are credited.

\begin{abstract}
Objective: To determine whether the amplitude of the sound evoked triceps myogenic potential (SETMP) scales with the tonic force exerted by the muscle.

Study design: A prospective study of myogenic potentials was conducted in 16 normal subjects. A monaural acoustic stimulus was presented to subjects while they while they exerted varying degrees of force with the triceps muscles. Subjects were required to activate the triceps by leaning into pressure transducers placed at shoulder height thereby supporting their body weight. The unrectified myogenic potential was collected using response triggered averaging of the signal from surface electromyogram (EMG) electrodes placed over the triceps bilaterally.
\end{abstract}

Setting: University affiliated otoneurology clinic.

Patients: Sixteen healthy adult volunteers (8 females, 8 males), age ranging from age 17 to 57 years (mean 32 years).

Main outcome measures: Latencies (msec) and amplitudes $(\mu \mathrm{V})$ of the first two waves of the evoked response.

Results: At 5, 10, 15 and $20 \mathrm{lbs}$. of force, the mean amplitudes of the ipsilateral SETMP responses were 27.32, $48.59,56.35$ and $106.41 \mu \mathrm{V}$, respectively, while the mean amplitudes of the contralateral SETMP responses were $48.42,72.21,72.67$ and $111.25 \mu \mathrm{V}$, respectively.

Conclusions: The amplitude of the SETMP response scales approximately linearly with the force of activation of the triceps muscle, and is fairly symmetrical.

Keywords: Vestibular; Evoked potentials; Cervical spinal cord; Triceps

\section{Introduction}

Loud sounds stimulate the saccule [1-5]. Once stimulated, the saccule generates a signal that travels through the inferior division of the vestibular nerve to the lateral vestibular nucleus [6-8]. From there the pathway projects through the spinal cord, possibly via the vestibulospinal tract [9], and synapses on interneurons and alpha motor neurons that innervate skeletal muscles. The saccule's signal modulates the surface electromyogram (EMG), and the effect can be measured using response triggered averaging. Very similar responses can be elicited using galvanic stimuli, which are silent [10], and the sound induced response can be recorded in certain subjects with sensorineural deafness [11]. For these reasons, the potential elicited by loud sounds is called a vestibular evoked myogenic potential (VEMP).

The conventional method of obtaining a VEMP is to present a train of clicks or tone bursts to one ear and to measure the averaged myogenic potential from the ipsilateral tonically contracted sternocleidomastoid (SCM) $[4,12]$. Tone bursts are preferable to clicks because the response can be obtained at lower stimulus thresholds [13-15] and they elicit responses of greater amplitude [16]. Studies of the SCM VEMP show that the amplitude of the response scales nearly linearly with the force of muscle activation [13,16-19].

VEMPs elicited by loud sounds have also been studied in other muscles such as neck extensors [20,21], erectores spinae, and extraocular muscles $[22,23]$. We previously established the existence of a sound evoked myogenic potential in the tonically activated triceps muscle when that muscle is serving the purpose of postural support [24], and have called this the "sound evoked triceps myogenic potential" (SETMP). The purpose of the current study is to examine whether the amplitude of the SETMP response scales with the amount of force exerted by the triceps in a fashion similar to the SCM VEMP.

\section{Materials}

\section{Subjects}

Sixteen subjects ( 8 females, 8 males), age ranging from 17 to 57 years (mean 32) were enrolled in the study after giving written informed consent. No subject had a history of hearing loss, tinnitus, 
Page 2 of 4

vertigo, or was using vestibular suppressant medications. Each subject underwent a screening otoneurological examination, audiogram and immittance testing, and the results for each subject were normal. Normal subjects were used for this study so that any force scaling effect was not likely to be affected by the presence of vestibular or musculoskeletal pathology. This study was approved by Northwestern University Feinberg School of Medicine's Institutional Review Board.

\section{Methods}

The method for eliciting sound evoked triceps myogenic potentials has been described elsewhere [24]. In brief, surface EMG electrodes were applied in the manner described by Cherchi et al (2009), with feet shoulder width apart, arms held forward with hands at shoulder level (fingers pointing up), with elbows flexed at $160^{\circ}$, and head facing forward. Each hand was pressing against a single wall-mounted pressure transducer (Pelouze Digital Receiving Scale model PEL4010). The distance of the subject's feet from the wall was adjusted until the wall-mounted pressure transducer registered 5, 10, 15 and $20 \mathrm{lbs}$. $(2.27,4.54,6.80$ and $9.07 \mathrm{~kg})$ in order to maintain a consistent level of tonic triceps activation.

Responses were obtained by averaging the acoustically evoked, unrectified EMG activity of the triceps during contraction. Rarefaction tone burst stimuli at a frequency of $500 \mathrm{~Hz}$, with a rise and fall of 6.00 msec each, with no plateau, and with a repetition rate of $4.3 / \mathrm{sec}$, were presented monaurally at $95 \mathrm{~dB}$ HL ( $132 \mathrm{~dB}$ peak SPL) via ER3A insert earphones. We used a 30-3000 $\mathrm{Hz}$ band-pass filter, averaged 500 stimuli for each trial, and used an epoch time of $106.6 \mathrm{msec}$. Responses were recorded using the Bio-Logic Navigator Pro evoked potential software (Bio-Logic Systems Corp, Mundelein, Illinois) and were combined in a weighted average from which we measured the latencies and amplitudes of the first positive and negative waves, $\mathrm{p} 1$ and $\mathrm{n} 1$.
With right ear stimulation, ipsilateral and contralateral responses were sought at triceps forces of 5, 10, 15 and $20 \mathrm{lbs}$. With left ear stimulation, an ipsilateral response (i.e., from the left triceps) and contralateral response (i.e., from the right triceps) was sought at only a single triceps force of 15 lbs. in all subjects because the experimental protocol is fatiguing, but we wanted to test at least one force level for the purpose of assessing the symmetry of the response.

In all subjects tested for a given force level testing condition we tracked the mean, the range, and the 95\% confidence interval of the latencies of the $\mathrm{p} 1$ and $\mathrm{n} 1$ responses, the interpeak latency and the interpeak amplitude. We calculated the Pearson product moment correlation coefficient for all available ipsilateral responses, and then for all contralateral responses. We calculated the degree of symmetry of all contralateral responses using Jongkees' formula.

\begin{tabular}{|l|l|l|l|l|}
\hline & \multicolumn{2}{|l|}{ Left ear stimulation } & \multicolumn{2}{l|}{ Right ear stimulation } \\
\hline Force & $\begin{array}{l}\text { Ipsilateral } \\
\text { response (left } \\
\text { triceps) }\end{array}$ & $\begin{array}{l}\text { Contralateral } \\
\text { response (right } \\
\text { triceps) }\end{array}$ & $\begin{array}{l}\text { Ipsilateral } \\
\text { response } \\
\text { (right triceps) }\end{array}$ & $\begin{array}{l}\text { Contralateral } \\
\text { response (left } \\
\text { triceps) }\end{array}$ \\
\hline $5 \mathrm{lbs}$. & Not tested & 6 tested (38\%) & $\begin{array}{l}3 \\
(19 \%)\end{array}$ & 5 tested \\
\hline $10 \mathrm{lbs}$. & Not tested & Not tested & $\begin{array}{l}51 \%) \\
(31 \%)\end{array}$ & 10 tested $(63 \%)$ \\
\hline $15 \mathrm{lbs}$. & $\begin{array}{l}2 \\
(13 \%)\end{array}$ & 14 tested (88\%) & $\begin{array}{l}2 \\
(13 \%)\end{array}$ & 10 tested (63\%) \\
\hline $20 \mathrm{lbs}$. & Not tested & 4 tested (25\%) & $\begin{array}{l}3 \\
(19 \%)\end{array}$ & 5 tested \\
\hline
\end{tabular}

Table 1: Number of subjects (and percentage of total subjects) tested in each test condition

\begin{tabular}{|c|c|c|c|c|c|c|c|c|c|}
\hline & & \multicolumn{4}{|l|}{ Ipsilateral } & \multicolumn{4}{|l|}{ Contralateral } \\
\hline & & $\begin{array}{l}\text { p1 latency } \\
\text { (msec) }\end{array}$ & $\begin{array}{l}\mathrm{n} 1 \text { latency } \\
\text { (msec) }\end{array}$ & $\begin{array}{l}\text { Interpeak latency } \\
\text { (msec) }\end{array}$ & $\begin{array}{l}\text { Interpeak } \\
\text { amplitude }(\mu \mathrm{V})\end{array}$ & $\begin{array}{l}\text { p1 latency } \\
\text { (msec) }\end{array}$ & $\begin{array}{l}\mathrm{n} 1 \text { latency } \\
\text { (msec) }\end{array}$ & $\begin{array}{l}\text { Interpeak latency } \\
\text { (msec) }\end{array}$ & $\begin{array}{l}\text { Interpeak } \\
\text { amplitude }(\mu \mathrm{V})\end{array}$ \\
\hline \multirow{3}{*}{$5 \mathrm{lbs}}$. & Mean & 37.16 & 42.64 & 5.48 & 27.32 & 36.79 & 43.4 & 6.59 & 48.42 \\
\hline & Range & $36.88-37.51$ & $41.88-43.96$ & $4.37-6.87$ & $24.42-30.67$ & $34.56-40.41$ & $40.91-49.05$ & $3.96-8.46$ & $19.83-96.29$ \\
\hline & $95 \% \mathrm{Cl}$ & $36.80-37.52$ & $41.35-43.94$ & $4.04-6.92$ & $23.75-30.88$ & $35.80-37.78$ & $42.03-44.77$ & $5.60-7.58$ & $34.53-62.30$ \\
\hline \multirow{3}{*}{10 lbs. } & Mean & 36.42 & 43.82 & 7.39 & 48.59 & 36.96 & 42.78 & 5.93 & 72.21 \\
\hline & Range & $34.59-37.09$ & $42.09-45.72$ & $5.00-10.21$ & $25.18-95.99$ & $34.35-39.99$ & $39.56-48.01$ & $3.12-8.02$ & $17.55-175.19$ \\
\hline & $95 \% \mathrm{Cl}$ & $35.52-37.33$ & $42.43-45.20$ & $5.42-9.37$ & $24.59-72.59$ & $36.19-37.72$ & $41.60-43.96$ & $5.19-6.67$ & $50.67-93.75$ \\
\hline \multirow{3}{*}{$15 \mathrm{lbs}}$. & Mean & 36.78 & 42.92 & 6.14 & 56.35 & 36.34 & 42.46 & 6.12 & 72.67 \\
\hline & Range & $35.84-38.13$ & $41.88-44.17$ & $3.75-7.70$ & $26.25-103.46$ & $33.35-38.72$ & $39.16-46.14$ & $2.39-9.99$ & $11.44-172.14$ \\
\hline & $95 \% \mathrm{Cl}$ & $35.83-37.73$ & $41.97-43.88$ & $4.49-7.79$ & $23.16-89.53$ & $35.71-36.98$ & $41.71-43.22$ & $5.27-6.97$ & $52.89-92.45$ \\
\hline \multirow{3}{*}{$20 \mathrm{lbs}}$. & Mean & 36.19 & 43.27 & 7.08 & 106.41 & 38.08 & 43.78 & 5.7 & 111.25 \\
\hline & Range & $35.01-36.88$ & $42.09-43.97$ & $5.21-8.75$ & $75.38-164.65$ & $36.95-40.18$ & $39.35-46.03$ & $2.39-8.33$ & $25.18-175.19$ \\
\hline & $95 \% \mathrm{Cl}$ & $35.03-37.35$ & $42.11-44.44$ & $5.07-9.10$ & $49.29-163.53$ & $36.67-39.48$ & $40.82-46.74$ & $3.18-8.22$ & $41.49-181.00$ \\
\hline
\end{tabular}

Table 2: SETMP results 
Page 3 of 4

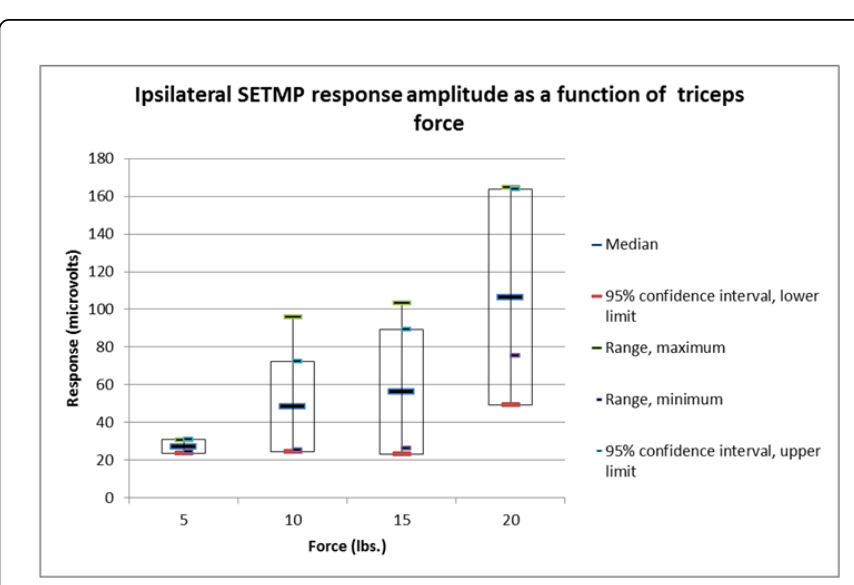

Figure 1: Whisker plot of ipsilateral SETMP response amplitude as a function of triceps force

\section{Results}

Not all subjects were tested in all conditions, as shown in Table 1. The SETMP response could be elicited in all subjects, but not at all force levels in each subject. At all force levels, responses were present more frequently contralaterally than ipsilaterally, as shown in Table 2. The results for $\mathrm{p} 1$ latency, $\mathrm{n} 1$ latency, interpeak latency, and interpeak amplitude at each of the force conditions are shown in Table 2. When a response was absent, its amplitude was recorded as zero and included in amplitude calculations, whereas its latencies were omitted from the calculations. Whisker plots of the ipsilateral and contralateral response amplitudes are shown in Figures 1 and 2.

The Pearson product moment correlation coefficient between the force exerted by the ipsilateral triceps and the amplitude of the response was 0.945 , while that between the force exerted by the contralateral triceps and the amplitude of the response was 0.938 .

Data from 8 subjects were available to compare the symmetry of the contralateral SETMP response that is comparing the amplitude of the "left ear to right triceps" response with the "right ear to left triceps" response. Symmetry calculated using Jongkees' formula (25) had a mean of 0.24 (range $0.09-0.46,95 \%$ CI $0.12-0.35$ ), where 0 is perfect symmetry.

\section{Discussion}

The data show that in normal subjects there is a strong correlation between the amount of force exerted, and the amplitude of the response, both ipsilateral and contralateral to the acoustic stimulus. There is a moderate degree of symmetry of the contralateral response between the two ears. Although the amplitude of the contralateral response is consistently greater than that of the ipsilateral response at each force level, this difference did not meet statistical significance, which is consistent with our prior study [24]. Although applying a force of $20 \mathrm{lbs}$. elicits a larger response, few subjects were able to perform this testing condition, whereas most subjects were able to exert 15 lbs. of force.

We previously established several key differences between the conventional SCM VEMP and the SETMP [24]. First, whereas the conventionally employed SCM VEMP is generally elicited while the subject is simultaneously activating both sternocleidomastoid muscles in a position (flexing the neck anteriorly) which is not posturally dependent, we have previously shown that the SETMP requires that the activation of the triceps muscle be relevant for maintenance of posture in order for the response to be elicited. Second, whereas the conventionally employed SCM VEMP response is generally greater ipsilateral to the acoustic stimulus (and often completely absent contralaterally) $[4,12]$, the SETMP response is present bilaterally, and tends to be greater contralaterally (though not to a degree that is statistically significant). The present study highlights an important similarity between the conventional SCM VEMP and the SETMP, namely that the greater the degree of tonic muscle contraction, the larger the amplitude of the response - in other words, there is a forcescaling relationship.

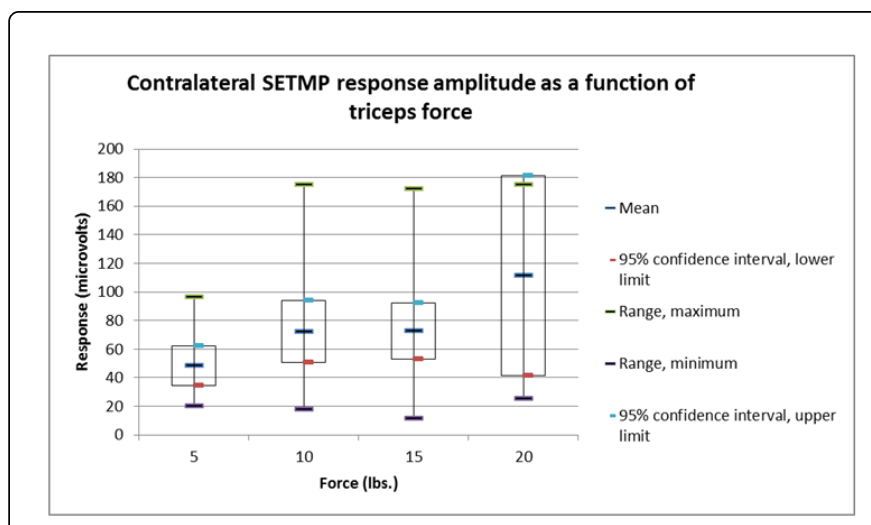

Figure 2: Whisker plot of contralateral SETMP response amplitude as a function of triceps force

Characteristics of the SETMP response that remain to be studied include how the response scales with the intensity of the stimulus, and whether there is a specific stimulus frequency or range of frequencies that elicits the most robust response.

Characterizing the SETMP response expands the repertoire of this evoked potential. It may also extend the clinical application by enabling assessment of patients who are unable to perform the more conventional SCM VEMP (for example, due to limited cervical range of motion). Using the SETMP testing condition of applying $15 \mathrm{lbs}$. of force may be optimal since it produced a relatively robust response, and could be performed by most of the subjects.

\section{Conclusion}

In normal subjects the amplitude of the SETMP scales approximately linearly with the force of triceps activation, and the response is symmetrical. This result is similar to that found for the SCM VEMP.

\section{Acknowledgement}

This research was supported by a National Research Service Award (NRSA 1F32DC009154-01A2) from the National Institute on Deafness and Other Communication Disorders (National Institutes of Health), and by the Georgia Birtman Grant Initiative Otoneurology Fellowship, which was jointly funded by the American Hearing Research Foundation and Northwestern Medical Foundation. 
Citation: Cherchi M, El-Kholy W, Shirley D, Hain TC (2015) Amplitude of Sound Evoked Triceps Myogenic Potential Scales with Force. J Neurol Neurophysiol 6: 286. doi:10.4172/2155-9562.1000286

Page 4 of 4

\section{References}

1. Bickford Rg, Jacobson Jl, Cody Dt (1964) Nature of average evoked potentials to sound and other stimuli in man. Ann N Y Acad Sci 112: 204-223.

2. Cody Dt, Jacobson Jl, Walker Jc, Bickford Rg (1964) Averaged evoked myogenic and cortical potentials to sound in man. Ann Otol Rhinol Laryngol 73: 763-777.

3. Colebatch JG, Halmagyi GM (1992) Vestibular evoked potentials in human neck muscles before and after unilateral vestibular deafferentation. Neurology 42: 1635-1636.

4. Colebatch JG, Halmagyi GM, Skuse NF (1994) Myogenic potentials generated by a click-evoked vestibulocollic reflex. J Neurol Neurosurg Psychiatry 57: 190-197.

5. Colebatch JG, Rothwell JC, Bronstein A, Ludman H (1994) Click-evoked vestibular activation in the Tullio phenomenon. J Neurol Neurosurg Psychiatry 57: 1538-1540.

6. Carleton SC, Carpenter MB (1983) Afferent and efferent connections of the medial, inferior and lateral vestibular nuclei in the cat and monkey. Brain Res 278: 29-51.

7. Cesaro P, Keravel Y, Ollat H (1995) Le cerveau et la moëlle épinière Lyon: ANNP (Association pour la neuro-psycho-pharmacologie).

8. Stein MB, Carpenter MB (1967) Central projections of portions of the vestibular ganglia innervating specific parts of the labyrinth in the rhesus monkey. Am J Anat 120: 281-318.

9. Nyberg-Hansen $\mathrm{R}$ (1970). Anatomical aspects on the functional organization of the vestibulospinal projection, with special reference to the sites of termination. NASA, SP-187: 167-81.

10. Watson SR, Colebatch JG (1998) Vestibulocollic reflexes evoked by short-duration galvanic stimulation in man. J Physiol 513 : 587-597.

11. Akin FW, Murnane OD (2001) Vestibular evoked myogenic potentials: preliminary report. J Am Acad Audiol 12: 445-452.

12. Murofushi T, Matsuzaki M, Wu CH (1999) Short tone burst-evoked myogenic potentials on the sternocleidomastoid muscle: are these potentials also of vestibular origin? Arch Otolaryngol Head Neck Surg 125: 660-664.

13. Basta D, Todt I, Ernst A (2005) Normative data for P1/N1-latencies of vestibular evoked myogenic potentials induced by air- or boneconducted tone bursts. Clin Neurophysiol 116: 2216-2219.
14. Welgampola MS, Colebatch JG (2001) Characteristics of tone burstevoked myogenic potentials in the sternocleidomastoid muscles. Otol Neurotol 22: 796-802.

15. Welgampola MS, Rosengren SM, Halmagyi GM, Colebatch JG (2003) Vestibular activation by bone conducted sound. J Neurol Neurosurg Psychiatry 74: 771-778.

16. Akin FW, Murnane OD, Proffitt TM (2003) The effects of click and toneburst stimulus parameters on the vestibular evoked myogenic potential (VEMP). J Am Acad Audiol 14: 500-509.

17. Akin FW, Murnane OD, Panus PC, Caruthers SK, Wilkinson AE, et al. (2004) The influence of voluntary tonic EMG level on the vestibularevoked myogenic potential. J Rehabil Res Dev 41: 473-480.

18. Lim CL, Clouston P, Sheean G, Yiannikas C (1995) The influence of voluntary EMG activity and click intensity on the vestibular click evoked myogenic potential. Muscle Nerve 18: 1210-1213.

19. Ochi K, Ohashi T, Nishino H (2001) Variance of vestibular-evoked myogenic potentials. Laryngoscope 111: 522-527.

20. Sakakura K, Takahashi K, Takayasu Y, Chikamatsu K, Furuya N, et al (2005) Novel method for recording vestibular evoked myogenic potential: minimally invasive recording on neck extensor muscles. Laryngoscope 115: 1768-1773.

21. Wu CH, Young YH, Murofushi T (1999) Tone burst-evoked myogenic potentials in human neck flexor and extensor. Acta Otolaryngol 119: 741-744.

22. Rosengren SM, McAngus Todd NP, Colebatch JG (2005) Vestibularevoked extraocular potentials produced by stimulation with boneconducted sound. Clin Neurophysiol 116: 1938-1948.

23. Todd NP, Rosengren SM, Aw ST, Colebatch JG (2007) Ocular vestibular evoked myogenic potentials (OVEMPs) produced by air- and boneconducted sound. Clin Neurophysiol 118: 381-390.

24. Cherchi M, Bellinaso NP, Card K, Covington A, Krumpe A, et al. (2009) Sound evoked triceps myogenic potentials. Otol Neurotol 30: 545-550.

25. Jongkees LB, Maas JP, Philipszoon AJ (1962) Clinical nystagmography. A detailed study of electro-nystagmography in 341 patients with vertigo. Pract Otorhinolaryngol (Basel) 24: 65-93. 